\title{
Level of Serum Uric Acid Along with Other Demographic Parameters in Patients with Acute Coronary Syndrome : A Study of 55 Cases from Chittagong
}

\author{
Hasan Murad ${ }^{1 *}$ \\ Rajiv Dey ${ }^{\top}$ \\ Md Atiquel Islam Chowdhury ${ }^{2}$ \\ Hridi Hedayet Ullah ${ }^{2}$ \\ Md Abdur Rouf ${ }^{2}$
}

\author{
'Department of Cardiology \\ University of Science and Technology (USTC) \\ ${ }^{2}$ Department of Medicine \\ University of Science and Technology (USTC)
}

\section{${ }^{*}$ Correspondence to:}

\section{Dr. Hasan Murad}

Assistant Professor

Department of Cardiology

University of Science \& Technology, Chittagong (USTC)

Chittagong, Bangladesh.

Mobile: +8801819383872

E-mail: nuhams.dx@gmail.com

\begin{abstract}
The association between serum uric acid and ischemic heart disease remains controversial and it has been difficult to identify the specific role of elevated serum uric acid because of its association with established cardiovascular risk factors such as hypertension, diabetes mellitus, hyperlipidaemia and obesity. Our objective was to study the association of serum uric acid level with confirmed cases of Acute Coronary Syndrome i,e. Unstable Angina, Acute Myocardial Infarction(AMI). The study was conducted in Chittagong Medical College (CMC) \& University of Science and Technology(USTC) and nearby diagnostic centre. The study was based on Patients with Acute Coronary Syndrome proved by ECG and/or raised serum Troponin I. The aim of the study was to determine the relationship between serum uric acid and Unstable angina or myocardial infacrtion. There were $35 \%$ males \& $5 \%$ females. The mean age of respondent was 50 years and age ranges from 35 to 70 years. In this study 50 cases of diagnosed myocardial infarction were selected and subsequently investigated with ECG, Radiological and Echocardiographic investigations. Increased serum uric acid levels are a common finding in patients with high blood pressure, insulin resistance, obesity and Cardiovascular disease. The clinical findings, chest X-ray and ECG findings of patients with risk factors for myocardial infarction were extensively studied and the findings are consistent with findings stated in textbooks.
\end{abstract}

Key words: Serum uric acid; myocardial infarction; unstable angina.

\section{INTRODUCTION}

The association between serum uric acid and ischemic heart disease remains controversial and it has been difficult to identify the specific role of elevated serum uric acid because of its association with established cardiovascular risk factors such as hypertension, diabetes mellitus, hyperlipidaemia and obesity ${ }^{1}$. Uric acid is a heterocyclic compound of carbon, nitrogen, oxygen, and hydrogen with the formula $\mathrm{C} 5 \mathrm{H} 4 \mathrm{~N} 4 \mathrm{O} 3$. Although uric acid can act as an antioxidant, excess serum accumulation is often associated with cardiovascular dsease ${ }^{2}$. Uric acid is a product of the metabolic breakdown of purine nucleotides. High blood concentrations of uric acid can lead to gout. This is associated with other medical conditions including diabetes and the formation of ammonium acid urate kidney stones. A relationship between hyperuricemia and CV disease has been established since the 1900's. Increased uric acid serum levels are a common finding in patients with high blood pressure, insulin resistance, obesity and CV disease. Myocardial infarction (acute coronary syndrome) is the medical term for an event commonly known as a heart attack. It happens when blood stops flowing properly to part of the heart and the heart muscle is injured due to not receiving enough oxygen. Usually this is because one of the coronary arteries that supplies blood to the heart develops a blockage due to an unstable buildup of white blood cells, cholesterol and fat. The event is called "acute" if it is sudden and serious. A person having an acute MI usually has sudden chest pain that is felt behind the breast bone and sometimes travels to the left arm or the left side of the neck. Additionally, the person may have shortness of breath, sweating, nausea, vomiting, abnormal heartbeats, and anxiety. 


\section{MATERIALS \& METHODS}

This is an observational stud for which the data for this study is obtained from University of Science and Technology (USTC) and Chittagong Medical College. A total of 55 primary sampling units were selected for this survey where 47 are male and 8 are female. In this survey, a total of $46 \%$ of them are aged between 51-60 and Body mass unit of $71 \%$ of them are between $51-70 \mathrm{~kg}$. $78 \%$ of them contain normal uric acid range and rest $22 \%$ had crossed the range. The Questionnaire was used to list all the usual respondent (having definite cardiac problem as evidenced by typical ECG changes and/or raised Troponin I) and Some basic information was collected on the characteristics of each person listed, including age, sex, BMI etc. The main purpose of the Questionnaire was to identify women and men who had cardiac problem. In addition, the questionnaire collected information about the habitual characteristics known as risk factors (i,e. Diabetes mellitus, Hypertension, Smoking etc).

Inclusion criteria: Age : 35 year to 70 year.Patients those who had Acute Coronary Syndrome (i,e.Unstable Angina/Non ST elevation Myocardial Infarction, Acute Myocardial infarction) as evidenced by typical ECG changes and/or typical rise of Troponi I are only inluded in the study.

Exclusion criteria: Those who are not having definite coronary artery disease are excluded from the study.

The statistical methods are applied on the analysis are as follows:

1. Chi-square ( $\mathrm{Bi}$-variate): To Study whether there is an association of dependent variable with socio economic and demographic characteristic of the study population chi square test statistic is performed after constructing the contingency table. The test statistic is,

$$
\chi^{2}=\sum_{i=1}^{n} \frac{\left(O_{i}-E_{i}\right)^{2}}{E_{i}} \sim \chi^{2}{ }_{(\mathrm{r}-1)(\mathrm{c}-1)} \mathrm{d} . \mathrm{f}
$$

Where the null and alternative hypothesis are as follows Ho : There is no association between dependent variable with the background characteristics.

$\mathrm{H} 1$ : There is an association between dependent variable with the background characteristics.

To assess the association between the dependent variable and the independent variables in this study, we performed chisquare tests. To ease the interpretations, our results have been expressed by estimated odds ratios (OR) with 95 per cent confidence interval (CI). All of the statistical analyses in this study have been performed by SPSS 16 .

Variables: This study includes some variables. They are divided into two groups: 1. Dependent variable, 2. Explanatory variables

Dependent variable: Uric Acid Range

Explanatory variables: They are Current age of respondent, sex of respondent, body mass index, Risk factor (DM), Risk factor (HTN), Risk factor (Smoking). The weighted frequency distributions of Respondents for various variables are discussed below.

\section{RESULTS}

The study used the primary study over 55 respondents having cardiac problem in Chittagong city. It was a survey of 55 respondents age between $30-80$ and their uric acid range is normal or not (where normal serum uric acid in case of Male: 3.4-7.0 $\mathrm{mg} / \mathrm{dl} \&$ female:2.4-5.7 $\mathrm{mg} / \mathrm{dl}$ ). In this study, the sample was made weighted by corresponding weighting factor provided for each of the respondent in survey data. The first section study deals with respondents (having cardiac problem) to examine their uric acid range status with other background characteristics (i.e Age,sex,weight etc). The second section of the study examines the effect of different risk factors (i,e. Diabetes Mellitus,Hypertension,smoking etc). Bi-variate statistical analyses were employed to assess the association between "uric acid range" and physical and habitual characteristics of the respondents. A binary response was created for the outcome variable "Uric acid range" for the respondent by the way that, if a respondent had uric acid range between $3.4-7.0 \mathrm{mg} / \mathrm{dl}$ (or $2.4-5.7 \mathrm{mg} / \mathrm{dl}$ for female), then she was coded as ' 0 ' and ' 1 ' for otherwise. Central tendency of dependent variable "uric Acid range" is,Mean: $5.3814 \mathrm{mg} / \mathrm{dl}$, Median: $5.50 \mathrm{mg} / \mathrm{dl}$, Mode: $5.20 \mathrm{mg} / \mathrm{dl}$. Chisquare test showing significant $p$ value $(0.250)$. Age of respondents those have cardiac problem, the leading age group is " $51-60$ " having almost $50 \%$ of total frequency, where Rest four age group contains not more than $20 \%$ of frequency individually (Fig. 1 ). From the graph of sex of respondents, it seems that risk of having cardiac problem for male is more than 5 times greater than female, where male contains $85 \%$ of frequency \& else are female (Fig.2). Here, almost $60 \%$ of respondent having cardiac problem in weight group $51-70(\mathrm{Kg})$ and other $40 \%$ are contributed by pre and post weight group of leading group(Fig:3). From the pie chart, the respondent having cardiac problem under observation, $78 \%$ between the normal range of uric acid (Male: $3.4-7.0 \mathrm{mg} / \mathrm{dl}$, female: $2.4-5.7 \mathrm{mg} / \mathrm{dl}$ ) and $22 \%$ is raised (Fig: 4) . From The graph for Risk factors of cardiac problem, It looks significant that among all respondent more than $50 \%$ is related (Positive) to all risk factors (Type 2 Diabetes Mellitus, Hypertension \& Smoking)(Fig.5).

Table 1: Range of uric acid (mg/dl) among patients with Acute Coronary Syndrome.

\begin{tabular}{lcccc} 
& Frequency & Percent & $\begin{array}{c}\text { Valid } \\
\text { Percent }\end{array}$ & $\begin{array}{c}\text { Cumulative } \\
\text { Percent }\end{array}$ \\
Normal & 43 & 78.2 & 78.2 & 78.2 \\
Others & 12 & 21.8 & 21.8 & 100.0 \\
Total & 55 & 100.0 & 100.0 & \\
\hline
\end{tabular}

Table 2: Levels of serum uric acid in different categories of Acute Coronary syndrome

\begin{tabular}{lccc} 
Diagnosis & $\begin{array}{c}\text { Normal serum } \\
\text { uric acid } \\
\text { (Male: } 3.4-7.0 \mathrm{mg} / \mathrm{dl} \text {, } \\
\text { female:2.4-5.7 mg/dl) }\end{array}$ & $\begin{array}{c}\text { Raised } \\
\text { serum uric acid }\end{array}$ & Total \\
NSTEMI & 4 & 1 & 5 \\
AMI (Inferior) & 13 & 5 & 18 \\
AMI (Anteroseptal) & 8 & 3 & 11 \\
AMI (Anterior) & 12 & 0 & 12 \\
Total & 37 & 9 & 46 \\
\hline
\end{tabular}


Chi-Square Tests

\begin{tabular}{|c|c|c|c|}
\hline & Value & df & $\begin{array}{c}\text { Asymp. Sig } \\
\text { (2-sided) }\end{array}$ \\
\hline Pearson Chi-Square & $4.106^{\mathrm{a}}$ & 3 & .250 \\
\hline Likelihood Ratio & 6.312 & 3 & .097 \\
\hline \multicolumn{4}{|l|}{ Linear-by-Linear } \\
\hline Association & 2.095 & 1 & .148 \\
\hline $\mathrm{N}$ of Valid Cases & 55 & & \\
\hline
\end{tabular}

a. 5 cells $(62.5 \%)$ have expected count less than 5 . The minimum expected count is .98 .

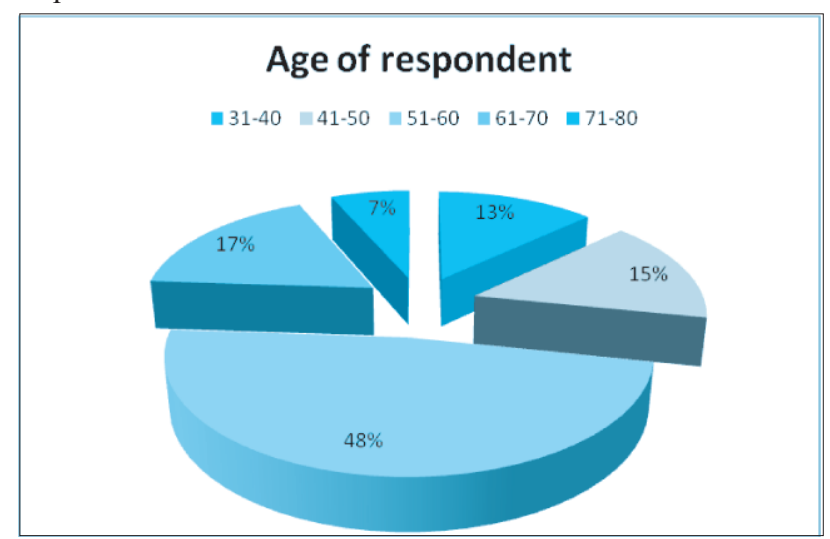

Figure 1 : Age distribution of patients with Acute Coronary Syndrome

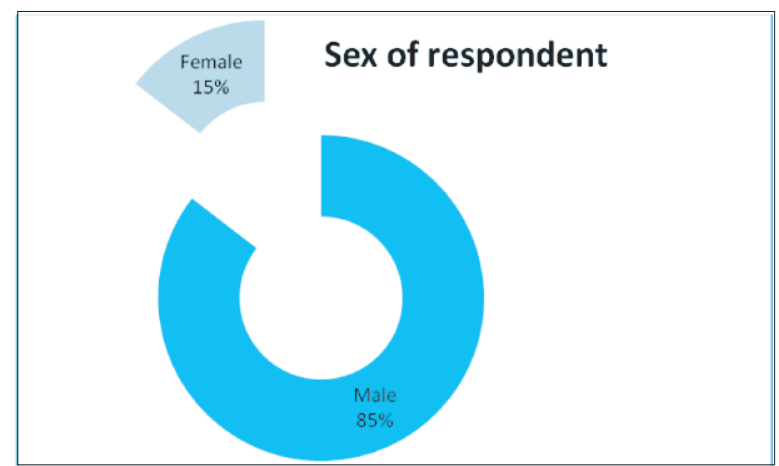

Figure 2 : Sex of patients with Acute Coronary Syndrome

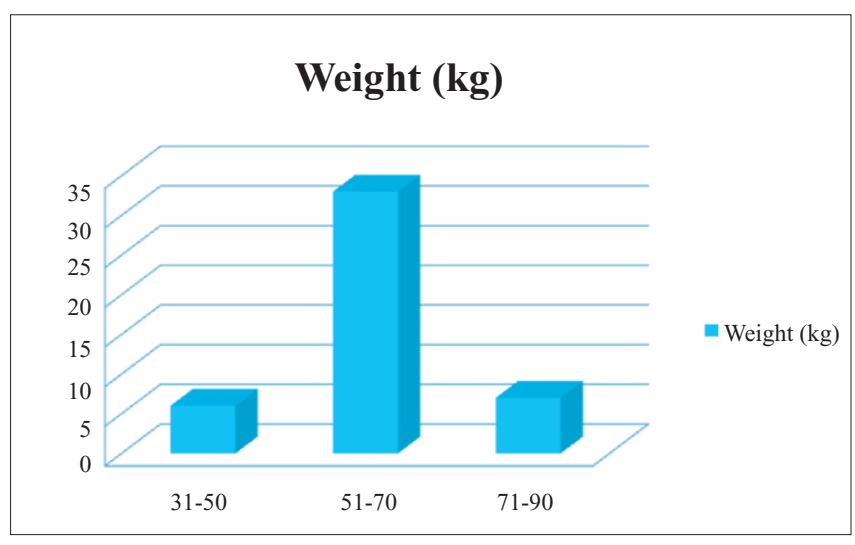

Figure 3 : Weight of patients having Acute Coronary syndrome

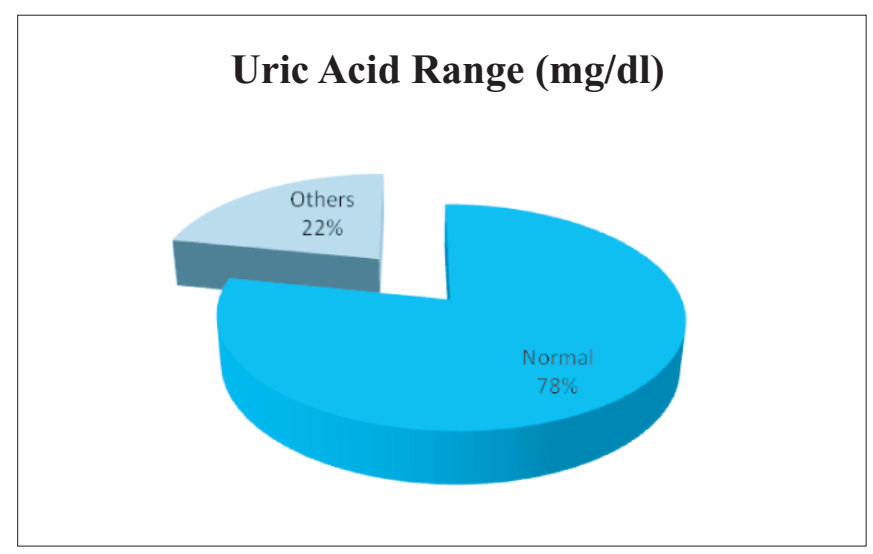

Figure 4 : Range of uric acid among patients with Acute Coronary Syndrome

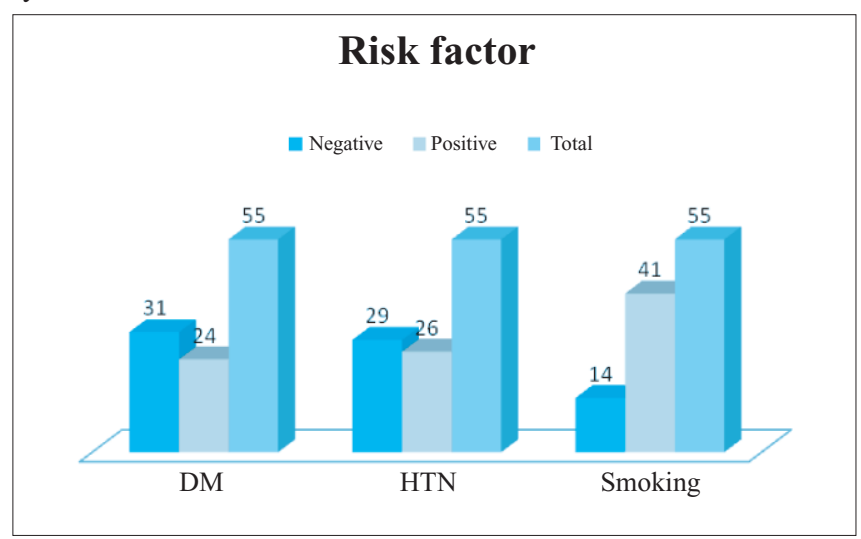

Figure 5 : Incidence of different risk factors in Acute Coronary Syndrome

\section{DISCUSSION}

Hyperuricemia is associated with risk for cardiovascular disease and death. However, the role of uric acid independent of established risk factors is uncertain ${ }^{3}$. Cardiac and visceral ischaemia promote generation of adenosine, which may serve as an important regulatory mechanism for restoring blood flow and limiting the ischaemia ${ }^{4}$. Adenosine synthesized locally by vascular smooth muscle in cardiac tissue is rapidly degraded by the endothelium to uric acid, which undergoes rapid efflux to the vascular lumen due to low intracellular $\mathrm{pH}$ and negative membrane potential ${ }^{5}$. Xanthine oxidase activity and uric acid synthesis are increased in vivo under ischaemic conditions, and therefore elevated serum uric acid may act as a marker of underlying tissue ischaemia. In the human coronary circulation, hypoxia, caused by transient coronary artery occlusion, leads to an increase in the local circulating concentration of uric acid ${ }^{6,7}$. This study also support this fact but further study with much increase number of sample size is warranted.

\section{CONCLUSION}

There is statistically significant relation found between hyperuricaemia and acute coronary syndrome but larger studies are required to further reconfirm the result to include serum Uric acid level as bio marker for cases of Acute Coronary Syndrome.

\section{DISCLOSURE}

All the authors declared no competing interest. 


\section{REFERENCES}

1. Bonora E, Targher G, Zenere MB, Saggiani F, Cacciatori V, Tosi F, Travia D, Zenti MG, Branzi P, Santi L, Muggeo M. Relationship of uric acid concentration to cardiovascular risk factors in young men. Role of obesity and central fat distribution. The Verona Young Men Atherosclerosis Risk Factors Study. Int J Obes Relat Metab Disord1996; 20:975-980.

2. Dawson J, Quinn T, Lees K, Walters M. The continued Yin and Yang of uric acid stroke. Stroke. 2008; 39: e9.

3. Culleton BF1, Larson MG, Kannel WB, Levy D. Serum uric acid and risk for cardiovascular disease and death: the Framingham Heart Study. Ann Intern Med. 1999 Jul 6;131 (1):7-13.

4. Fredholm BB, Sollevi A. Cardiovascular effects of adenosine. Clin Physiol1986;6:1-21. 5. Kroll K, Bukowski TR, Schwartz LM, Knoepfler D, Bassingthwaighte JB. Capillary endothelial transport of uric acid in guinea pig heart. Am J Physiol1992, 262:H420H431.

6. Castelli P, Condemi AM, Brambillasca C, Fundaro P, Botta M, Lemma M, Vanelli P, Santoli C, Gatti S, Riva E. Improvement of cardiac function by allopurinol in patients undergoing cardiac surgery. J Cardiovasc Pharmacol1995; 25:119-125.

7 Kogure K, Ishizaki M, Nemoto M, Kuwano H, Tatemoto K, Maruyama Y, Ikarashi Y, Makuuchi M. Evaluation of serum uric acid changes in different forms of hepatic vascular inflow occlusion in human liver surgeries. Life Sci1999; 64:305-313. 